\title{
Correction to: Impacts of early marriage and adolescent pregnancy on mental and somatic health: the role of partner violence
}

\author{
Aysen Ufuk Sezgin ${ }^{1} \cdot$ Raija-Leena Punamäki ${ }^{2}$ (I)
}

Published online: 18 May 2019

(C) Springer-Verlag GmbH Austria, part of Springer Nature 2019

\section{Correction to: Archives of Women's Mental Health https://doi.org/10.1007/s00737-019-00960-w}

The published version of the article contains an error in the author name and in the affiliation.

The authors wish to clarify that Ufuk Ausen Sezgin refers to Aysen Ufuk Sezgin. Additionally, the correct affiliation 1 should be Istanbul University, Istanbul Medical Faculty, Forensic Medicine Department.

The original article has been corrected.

Publisher's note Springer Nature remains neutral with regard to jurisdictional claims in published maps and institutional affiliations.

The online version of the original article can be found at https://oi.org/ 10.1007/s00737-019-00960-w

Raija-Leena Punamäki

Raija-leena.Punamaki@uta.fi; http://www.raijapunamaki.com/

1 Istanbul University, Istanbul Medical Faculty, Forensic Medicine Department, Istanbul, Turkey

2 Faculty of Social Sciences/Psychology, Tampere University, Kalevankatu 5, Linna 4krs, FIM-33014 Tampere, Finland 